\title{
"NÃO SEI NEM PORTUGUÊS, QUE DIRÁ INGLÊS": SENTIDOS DE DIZERES RECORRENTES DOS ALUNOS DE LÍNGUAS
}

\section{Márcia Rosetti de O. Albuquerque *}

Resumo: A maioria dos professores de língua inglesa já ouviu de seus alunos a formulação que dá título a este estudo, bem como algumas outras também constantemente repetidas em discursos sobre ensino/aprendizagem de línguas estrangeiras. Baseado na perspectiva teórico-metodológica da Análise do Discurso, que permite perscrutar a relação entre o lingüístico, o histórico e o ideológico nos processos de constituição dos sentidos, este traballho propõe uma análise de formulações recorrentes, estabilizadas na memória dos sujeitos nos espaços das instituições de ensino. O objetivo da análise é contribuir para a compreensão de sentidos que circulam no contexto sócio-histórico sobre o qual se assentam as atividades pedagógicas de ensino das línguas portuguesa e estrangeiras, buscando as determinações sociais, políticas e culturais que permitem uma prática social que é, ao mesmo tempo, repetível no fio do discurso e atravessada por vozes divergentes. O exame do repetivel no fio do discurso dos sujeitos estudantes de línguas mostra como os sentidos se reproduzem e se rompem - entre o estabilizado e o contraditório - trabalhando efeitos imaginários que constroem as imagens que os sujeitos têm das línguas, das relações entre elas, bem como o modo como eles se representam no jogo simbólico-imaginário dos processos de identificação entre o espaço nacional e o mundo dito globalizado.

Palavras-chave: Discurso; Lingua portuguesa; Lingua inglesa; Sentidos; Aprender. Ensinar

A análise apresentada neste trabalho faz parte do projeto Os Sentidos do Discurso de Ensinar e Aprender Inglês como Lingua Estrangeira, em andamento no Programa de Pós-Graduação em Letras e Lingüística, da Universidade Federal de Alagoas, e trata de investigar os sentidos que a língua estrangeira, instalada nas várias esferas sociais, está produzindo, que espaços esses sentidos estão preenchendo, o que os sustenta e em que condiçōes sócio-históricas eles se definem no contexto escolar e fora dele.

Para alcançar meu objetivo faço uso da perspectiva teórica e metodológica da Análise do Discurso porque nesse campo de estudo, é possível

Professora Adjunta de Língua Inglesa da Faculdade de Ictras, da Universidade Federal de Alagoas, atuando na Graduação em lectras c no Programa de Pós-Graduação em Letras e Lingüistica. 
observar não só as classes e falas dos alunos e professores, mas também o contexto social e histórico sobre o qual se assentam as práticas em foco. Sendo o que Pêcheux chama de disciplina de entremeio, através dela, investigo o exterior das salas de aula enquanto constitutivo do interior. O trabalho se realiza no espaço em que acontecem as relações entre uma determinada conjuntura histórica, com a ideologia e a língua, no caso a portuguesa e a inglesa, visando compreender para além dos efeitos de sentido, isto é, das interpretações permitidas aos sujeitos dos discursos analisados. Isso significa recuperar as condições de produção desses discursos, como se reproduzem e circulam, a que outras formulaçòes se associam, bem como o modo pelo qual o conjunto das formulações que compòem o corpus se relacionam a um acontecimento e convocam a memória para a atualidade.

A Análise do Discurso, portanto, permite um deslocamento de estudos sobre bases puramente lingüísticas (a língua em seu funcionamento interno) em seu contexto situacional imediato para o processo discursivo-ideológico, tendo a língua como base material para discursos que, por sua vez, constituemse em uma das formas de materialização da ideologia.

Orlandi (1999) afirma essa relaçào da seguinte forma:

Partindo da idéia de que a materialidade específica da ideologia é o discurso e a materialidade específica do discurso é a língua, [a Análise do Discurso] trabalha a relação lingua-discurso-ideologia. Essa relação se complementa com o fato de que, como diz M. Pêcheux (1975), não há discurso sem sujeito e não há sujeito sem ideologia: o individuo é interpelado em sujeito pela ideologia e é assim que a língua faz sentido (p. 17). [...] $[\mathrm{O}$ sujeito], por sua vez, se constitui na relação com o simbólico, na história (p. 19).

Para essa autora "discurso é efeito de sentidos entre locutores" (op.cit. p.21). Efeito porque seus sentidos são delimitados por determinaçòes históricas, ideológicas e sociais que sào condições para sua produção e nào estão, portanto, representando a realidade tal qual ela se apresenta. De fato, os discursos se constituem daquilo que Bakhtin (1992, p.86) chama de "milhares de fios ideológicos e estào, desse modo, interligados a outros dizeres, a compromissos políticos e a filiaçòes ideológicas.

Na atual conjuntura histórico-social de intensa valorizaçào da língua inglesa, o enfrentamento a que se submetem os sujeitos que tentam aprendêla dentro do campo de sua língua materna, isto é, no interior da formaçào 
social cuja interaçào verbal-social é feita em língua portuguesa, falada no Brasil, o lugar da memória é feito de imagens e representaçōes de si e do outro em um jogo em que os sujeitos dizem e se contradizem, se aproximam e se distanciam das línguas e das culturas, repetem, negam, transformam, avançam e retrocedem teorias e práticas em uma práxis cheia de contradiçòes.

Em termos gerais, o projeto de pesquisa que estou desenvolvendo examina características e concepções norteadoras do ensino-aprendizagem de inglês no contexto educacional atual, analisando os processos discursivos que constroem os efeitos de sentido que sustentam o papel da língua inglesa no contexto educativo brasileiro.

No quadro educacional moderno, trata-se de praticamente uma unanimidade a afirmaçào da importância da língua inglesa no elenco das disciplinas escolares. No entanto, na hierarquia existente na escola, onde algumas disciplinas têm mais valor do que outras, a língua estrangeira (inglês) funciona em posição subalterna, inferior a várias outras, ainda que, paradoxalmente, o estudo essa língua em cursos particulares de idiomas seja visto como imprescindível. Esse é um primeiro ponto que indica que as questòes relativas ao ensino de inglês como língua estrangeira no Brasil precisam ser aprofundadas e compreendidas em seu funcionamento efetivo.

Além do ambiente educacional, a inegável presença da língua inglesa na vida social brasileira (bem como na maior parte dos países da atualidade) demanda reflexòes sobre essa atuaçào nào somente enquanto exigência do chamado mundo globalizado, mas especialmente no que concerne às determinações históricas e ideológicas que desvelam os sentidos para além dos efeitos de interpretaçào e expòem pela via da observaçào do imaginário a ordem simbólica que os inscreve. Pela análise abrangente da conjuntura na qual o trabalho pedagógico com a língua inglesa se realiza, proponho compreender seu funcionamento e, a partir dessas bases, contribuir para que os professores de língua estrangeira possam discutir a o fato de que "sempre sob as palavras, outras palavras sào ditas [...] bem como "escutar a polifonia nào intencional" (AUTHIER-REVUZ, 1990, p.28) de seu discurso, seus posicionamentos e suas contradiçòes para, a partir daí, buscar transformá-lo. A análise dos principais conceitos que alimentam a conjuntura de ensino de língua estrangeira no Brasil é um modo de desvelar a ordem simbólica que constitui as filiaçoes identificadoras dos discursos fundadores do imaginário coletivo para, dessa forma,

Ajudar a compreender as atuais condições de existência as quais estamos submetidos e, conseqüentemente, 
dentro das condições materialmente postas, nos limites contraditórios das formações discursivas, avaliar as opções, mediadas pelo saber, das mais simples, como, por exemplo, as escolhas lingüisticas, às mais abrangentes, tais como, os parâmetros sociais e políticos sobre os quais desejamos compor e recompor nosso diálogo com o capitalismo e a globalização. (ALBUQUERQUE, 2003, p.16).

A análise que apresento a seguir se refere, basicamente, a um dizer que, no contexto de ensino de língua inglesa, é freqüentemente repetido tanto no nível fundamental e médio quanto na educaçào superior. "As práticas discursivas se fundam nào somente nas 'ideologias constituídas' (BAKHTIN, 1990, p.120) como a política e a educação, mas também naquilo que se costuma chamar de senso comum, isto é conteúdos e valores que circulam de forma desordenada, convergindo e dispersando os sentidos das atividades humanas" (ALBUQUERQUE, 2006, p.17). Sendo assim, afirmações constantemente re-inscritas no cotidiano das salas de aula podem mostrar sentidos e formas de identificaçào que os sujeitos envolvidos estào criando e recriando, reproduzindo e modificando no interior de sua formaçào social.

\section{Que sentidos de um dizer recorrente?}

Durante a minha vida profissional, nos vários niveis de ensino e em diferentes contextos (escolas públicas, privadas e técnica), uma mesma asserção se fazia ecoar onde quer que eu estivesse trabalhando. Um dizer que outros professores de inglês também ouviram repetidamente. $O$ fato é que a constante repetiçào me acabrunhava, fazia-me pensar e tentar dar sentido a um discurso tào amplamente compartilhado. Nào era exatamente o fato de que, em nível superficial, o meu encontro com a famosa asserçào não sei nem português, que dirá inglês se mostrava como uma afronta ou um desprezo pela disciplina que eu zelosamente buscava ensinar; havia mais, e eu queria conhecer esse algo mais sobre algo que estava plantado no terreno que eu pretendia semear.

Em princípio, duas indagações logo se puseram: por que pessoas fluentes em português negam saber essa língua (não sei nem português)? Quem dirá e o que dirá quanto ao fato de não ser viável aprender inglês (que dirá inglês)?

A materialidade lingüística apresenta uma negativa enfatizada pela conjunçào "nem" que poderia ser parafraseada por "sequer sei português" ou "nem ao menos sei português", implicando o fato de que essa era uma coisa que ele deveria saber. A segunda parte, "que dirá inglês" vem sem um sujeito 
para a terceira pessoa do singular do futuro do presente "dirá" e remete a uma gradação de intensidade cuja interpretaçào pode ser: alguém dirá que, para esses sujeitos, a aprendizagem do inglês está ainda mais distante/remota, em termos de possibilidade de alcançar.

Além dessa reflexão, três temas podem ser relacionados à formulação acima: 1. Que língua portuguesa é essa que o falante de português diz nào saber? 2. Por que o acesso à língua inglesa é ainda mais difícil? 3. Qual é a relaçào entre as duas línguas?

Essa última questão se justifica porque ambas as línguas ocupam amplo lugar nos currículos escolares, uma é língua materna e a outra é presença freqüente nos diversos contextos brasileiros, além de ser matéria educacional bastante valorizada nas várias camadas da sociedade.

\section{O Português que não sabemos}

Para desvelar as diferentes concepçōes acerca da língua portuguesa falada no Brasil e da língua inglesa enquanto língua estrangeira, este estudo se vale de construtos teórico-metodológicos apresentados por autores como Michel Pêcheux (1988 e 1990), Jean Jacques Courtine (1981), Paul Henry (1990), Jacqueline Authier-Revuz (1994), Eni Orlandi (1996, 1999) e outros que oferecem as categorias fundamentais para a compreensão do funcionamento do processo discursivo, dentre elas, o interdiscurso, as formaçòes ideológicas e as formaçòes discursivas. A partir de porçòes interdiscurso, definido como "algo que fala antes, em outro lugar, independentemente" (PÊCHEUX 1999, p. 162) as formaçòes discursivas se constituem e fornecem aos sujeitos "os elementos do saber que se organizam no interior de seu discurso", assim como permitem ao sujeito se significar, significar, re-significar seu dizer (INDURSKY, 2003, p.102).

A formação discursiva é, dessa forma, a interseção, no discurso, para onde convergem as possibilidades e as interdiçoes do dizer, as formaçòes ideológicas, por sua vez, são o "todo complexo dominante de uma formaçào discursiva” (PÊCHEUX, 1988, p.159), são a materializaçào da ideologia como traços coincidentes de sentido em relaçào às diversas áreas das relaçòes humanas. Em suma, esta é a base metodológica sobre a qual se apóia a análise dos efeitos de sentido circulantes acerca das línguas e seus papéis na sociedade.

Em minha tese de doutorado, identifiquei três formaçòes discursivas que dào sentido à língua portuguesa. Essas formaçòes discursivas promovem gestos de interpretaçào que produzem discursos fundadores do imaginário coletivo e deixam visíveis marcas de posicionamentos ideológicos e de processos 
de identificaçào. $O$ primeiro (não necessariamente em ordem de importância) se estabelece no âmbito político-institucional e se representa em documentos oficiais e através da voz do deputado Aldo Rebelo, da Academia Brasileira de Letras, de gramáticos como Evanildo Bechara e por associaçòes liderados por professores de português com o objetivo de defender a língua portuguesa. ${ }^{1} \mathrm{~A}$ segunda formação discursiva identificada é a voz da ciência, representada por renomados lingüistas como Bagno, Faracco, Schmitz, (ver FARACCO, 2001) e outros. Por fim, atribuí o nome de progressistas ao segmento que se compòe de profissionais ligados à economia e à informática, além de adeptos de diversas áreas. Na prática, essas três posiçòes constantemente se extrapolam e é possível, nos vários discursos, observar a presença de aspectos de uma delas em outra.

A língua portuguesa que o estudante diz nào saber é a que classifiquei sob o nome de político-institucional. Trata-se da língua culta, padrào, bonita, rica, autêntica, bela, pródiga, precisa, culta e pura. Essa é a língua que promove a unidade nacional, representa a identidade nacional, e é patrimônio cultural brasileiro. Além disso, é vista como uma língua difícil, complexa, prolixa, cheia de regras e exceçòes. Apresenta-se em discursos relacionados com tradição e nacionalidade e precisa ser defendida e protegida pelas leis que regem a sociedade. Ela é o elo que une as diferentes regiōes do país e constitui a identidade nacional. É, também, um sistema de regras autônomo, homogêneo cuja estabilidade deve ser preservada, é regida pelas leis da gramática e é a língua ideal, àquela que coincide com a variedade culta registrada nas obras de cultura erudita. As afirmaçòes que se seguem representam significativamente essa formaçào discursiva.

1.1. [a língua portuguesa] é a forma de expressão oral e escrita do povo brasileiro, tanto no padrão culto como nos moldes populares. Constitui bem de natureza imaterial integrante do patrimônio cultural brasileiro.

(Projeto de Lei $\mathrm{n}^{\circ} 1676 / 99$ art. $^{\circ}$ - II -III de autoria do deputado Aldo Rebelo) 1.2[...] ao contrário do que acontece nos outros países nós não temos uma consciência coletiva de que falando ou escrevendo corretamente o português praticamos um ato de afirmação da própria nacionalidade e do vigor das nossas raizes culturais. [...] é preciso ter vergonha e passarmos a ensinar melhor e respeitar os cânones do idioma. A cidadania encontra-se no uso adequado da língua portuguesa.

(A. Costa ,jornalista, O Globo, 19 de dezembro de 1997) (...)

Por exemplo, o Morimento de Defesa da I ingua Portuguesa da Baixada Santista. 
1.3 Precisávamos de algo para proteger a nossa língua portuguesa.

(Lygia Fagundes Telles, sobre o projeto que coibe estrangeirismos, para o jornal Estado de São Paulo, em 26 de março de 2000).

Ao se posicionar como alguém que nào sabe a língua materna, o estudante se coloca em uma posição de inferioridade como cidadão e em uma situação de incompetência para exercer sua cidadania e exigir direitos, ele nào representa a identidade nacional. De certa forma já se apresenta fracassado, diminuído, em sua incompetência lingüística, por nào ter capacidade plena de articular o pensamento, de afirmar sua nacionalidade e suas raízes culturais. Torna-se marginal em termos de futuro profissional, de vantagens e beneficios, é incompleto por não falar o português considerado correto, que é a língua valorizada.

A segunda formação discursiva que identifiquei se fundamenta em estudos lingüísticos. Para esse grupo a língua é autônoma e possui variantes regionais que devem ser respeitadas. Para esses estudiosos da lingüística que podem ser representados pelo grupo de autores do livro Guerra em torno da lingua, organizado por Faracco (2001), a normatizaçào da língua enquanto objeto homogêneo e unitário é ilusória, uma vez que o que mantém a língua em seu fluxo natural é a capacidade de variação (FIORIN, 2001). A língua é um sistema independente. Eles não se opòem à existência política da língua, aos direitos e deveres lingüísticos do cidadão e estào especialmente interessados em uma política educacional abrangente, porém rejeitam discursos nacionalistas de proteçào à língua que, nas palavras de Garcez e Zilles (2001, p.123), são "baseados no preconceito infundado de que há só uma língua na comunidade nacional, a língua padrão do poder".

2.1 O português do Brasil não "vai bem, obrigado" nem "vai mal, coitado", ele simplesmente vai, segue seu rumo, seu fluxo ditado por suas próprias forças constitutivas internas [...] as línguas são sistemas autoreguladores [...] Vamos deixar ela em paz, O.K? (BAGNO, 2001, p.173). 2.2 [...] temos mostrado o quão esquizofrênica é a sociedade brasileira quanto à questão da língua, temos combatido arraigados preconceitos lingüísticos que afetam tão insidiosamente as nossas relações sociais; temos denunciado a miséria da educação lingüística que se oferece na escola brasileira. (FARACCO, 2001, p.197) $2.3[\ldots]$ os modelos estáticos mascaram uma propriedade essencial da linguagem, seu dinamismo interno [...] A linguagem é uma relação de equilíbrio precário derivado 
de forças estabilizadoras e desestabilizadoras. (FIORIN, 2001, p.17).

Os lingüistas citados, bem como muitos outros, reconhecem que há uma distância entre a pesquisa lingüística e a prática educacional. Nào há, de forma consistente, na vida das instituiçòes escolares uma interaçào entre as concepçòes advindas de estudos lingüísticos e as instituições escolares, ainda que haja iniciativas isoladas. Sendo assim, de modo geral, os sentidos produzidos por essa formação discursiva nào estão presentes nos discursos dos estudantes.

Tanto os representantes da lingǘstica quanto os nacionalistas assumem como capacidade intrínseca da língua: a de articular o pensamento e a função de representar a cultura. Nesse sentido, ela é autônoma. Para os primeiros essa característica é motivo pelo qual ela deve ser defendida e oficialmente protegida como patrimônio cultural que representa a nacionalidade e a identidade. Os segundos, no entanto, vêem essa autonomia com mecanismos internos capazes de se auto regular sem interferências ("Vamos deixar ela em paz, OK?" 2.1).

A formação discursiva que nomeei de progressista se compõe de representantes da economia e da tecnologia e está atravessada por discursos políticos e econômicos, evidenciados no atual contexto sócio-histórico que promove determinados sentidos para o que se convencionou chamar de globalização. Entretanto, pode-se encontrar os ecos dessa formação nos discursos de sujeitos cujas formações discursivas estão predominantemente localizadas naquelas anteriormente citadas. Desse modo, afirmação como a que apresento a seguir se sustentam através de discursos que ensejam a inserção de um país "em desenvolvimento" no chamado primeiro mundo. As seqüências discursivas são exemplos desse grupo.

3.1 Nada de leis protecionistas. A lingua, como o computador e o carro e apenas um instrumento a servico do homem. E não um objeto de culto religioso. A lingua portuguesa não morreu. Ma comeca a cheirar mal. Esqueca se ela e bonita, ou se e rica, ou se e autentica. Esqueca as emocoes, esqueca o nacionalismo irracional (...) Em termos bem praticos para que serve a lingua portuguesa agora? A história da linguagem humana obedece a leis naturais e dinamicas (...) Uma lingua prolixa ao extremo, que conjuga seus verbos em um zilhão de modos diferentes. E um mastodonte atolado em regras. (Marquesi,1997). [o autor não utiliza acentos, cedilhas, etc. $O$ ingles tornou-se a lingua planetaria porque é pratica objetiva e economica (MARQUESI, 1997) 
3.2 Os idiomas são palco de mestiçagem, de interculturalidade e não devem ser vistos como baluartes ou fortalezas de nacionalidade. (SCHIMITZ, 2001)

3.3 Nosso idioma, apesar de regras por vezes tortuosas, e cheio de virtudes, (...) (Aldo Rebelo no seminário Idioma e Soberania: nossa língua, nossa Pátria)

Geralmente, o que está subjacente a discursos deste grupo é o fato de que há uma necessidade premente de alcançar os ideais de globalização, de êxito econômico, de alinhamento com os países ricos, de se relacionar com o resto do mundo, de ter acesso à tecnologia e à ciência, enfim de alcançar o bilingüísmo. Nesta formação discursiva, mesmo na fala radical do Marquesi, aparecem traços da língua institucional, do orgulho nacional "bonita, rica, e autêntica". Apesar de acreditar na necessidade de adaptar o português aos novos tempos, os valores aprendidos na escola ainda atravessam os discursos. Há uma tensão entre a tradição, a preservação de valores e raízes e a certeza de que para vencer é preciso fazer algumas concessōes.

Marquesi (3.1) pede aos leitores que esqueçam que a língua é "bonita, rica e autêntica"; o que ele propõe é não lembrar dessas qualidades, mas nào as nega. Suas palavras coincidem tanto com a voz nacionalista que exalta as virtudes da língua mãe (rica, bela, sonora) quanto com os ecos da "última flor do Lácio, inculta e bela", famoso verso do poeta Olavo Bilac. As afirmaçòes de Schimitz (3.2) e de Rebelo (3.3) estão longe de propor mudanças drásticas na língua portuguesa que Marquesi considera necessárias para que os brasileiros possam vencer no mundo moderno. No entanto, o imaginário que compõe os sentidos do que é a língua portuguesa atravessa as diferentes formações discursivas. Por esse motivo, a imagem de língua difícil se insere no discurso laudatório de Aldo Rebelo através da afirmação “apesar de regras por vezes tortuosas' (3.3). A rejeição a regulação externa da língua e a idéia de pureza lingüística da formação discursiva político-institucional aproxima o discurso de Schimitz (3.2) ao dos progressistas que também visam a mestiçagem e a interculturalidade e não idiomas tratados como baluartes da nacionalidade.

\section{Que dirá inglês}

No que se refere à relação do brasileiro com a língua inglesa, e retomando a segunda parte da formulação em destaque "que dirá inglês", partimos então do fato de que se a língua portuguesa nào é objeto alcançável, $o$ inglês é ainda mais remoto. 
A língua inglesa entra na prática discursiva brasileira simbolizada como uma necessidade vital para a sobrevivência econômica e social. Vigora na formaçào social brasileira a crença de que não se pode prescindir do inglês sem abrir mão da riqueza, da tecnologia e das relaçòes com o mundo (Ver Folha de S. Paulo, 30 agosto 1999, o suplemento Folhateen, com o texto Alfabeto para o mundo globalizado). A idéia é a de que quem tem inglês tem voz, existe, não está isolado ou atrasado e pode entrar no primeiro mundo. Ele é língua universal, fenômeno mundial, ajuda a realizar o sonho de conseguir bons empregos, está por toda parte, é língua do poder, do progresso e do prestígio. É um idioma necessário para aprimoramento profissional e para se ter acesso à ciência. Além disso, a língua inglesa é também considerada neutra por ser a língua franca, bem como é difundida como um instrumento para comunicaçào com outros povos. acima citada:

Veja, por exemplos, os conselhos oferecidos aos jovens na follhateen

Aprenda inglês senão você corre o risco de ser uma ilha cercada de inglês por todos os lados.

O diálogo científico acontece em inglês.

Para ser um cidadão do mundo globalizado, profissionalizado é preciso falar inglês, é o preço do ingresso para ser cidadão do mundo. Quem não fala inglês é amador, não compete com profissionais.

Saber inglês é útil não apenas em qualquer dimensão prática que se possa imaginar (uma mão de obra bilingüe, mais competitiva no mercado mundializado de trabalho) mas também para a cultura como um todo.

No discurso em que inglês não é objeto acessivel, nega-se também a possibilidade de fazer parte do mundo dos vencedores, dos bem-sucedidos. Dessa forma, aqueles que proclamam sua incapacidade de aprendê-la estão também afirmando sua impossibilidade de obter êxito em diversos aspectos importantes de seu crescimento pessoal.

Em oposição ao prestígio dessa língua, aparecem, de forma recorrente, nos discursos de cidadàos brasileiros, os termos contaminação, invasào, empobrecimento cultural, perda da identidade cultural, infiltraçào absurda que deve ser controlada em referência à presença da língua inglesa no Brasil. A defesa da pureza da língua vem sempre acompanhada da preocupação com a unidade do país. A memória discursiva aciona uma concepção de língua como elemento fundador e unificador da nacionalidade. A 
contaminação da língua, em oposição à sua limpeza teria como conseqüência o desmantelamento cultural e a dispersão da pertença, dos pontos em comum que fazem com que um grupo se identifique como um povo (ALBUQUERQUE, 2006, p.12).

Por outro lado, o prestígio do inglês constitui o imaginário que convoca essa língua como representante do modelo econômico, cultural e científico da nova realidade mundial. O contexto educacional é atravessado por ambos, e o discurso dos estudantes mostra essa tensão entre o nacional e o global. $O$ português que eles não sabem e o inglês ainda mais distante na vida estudantil de um número significativo de brasileiros são bastante reveladores da ideologia que dá suporte a processos de identificação de sujeitos que são brasileiros e que acreditam nào dominar o idioma de sua pátria, mas, ao mesmo tempo, vêem como remota a aprendizagem de uma língua que, nas atuais condiçòes históricas, se faz necessária para ser bem sucedido no mundo moderno.

\section{Como se relacionam as línguas portuguesa e inglesa?}

Ambos os discursos, o da preservação e o do multiculturalismo, estão inscritos no imaginário sobre as línguas e culturas e têm formas de representação na sociedade.

A noção de que aprender inglês é essencial para o sucesso profissional e o registro simbólico que produz a imagem da sociedade e da cultura americana estào marcados em uma série de conceitos que perpassam a prática discursiva do brasileiro. Um exemplo disso é a atribuiçào de dificuldade de aprender a língua portuguesa. É essa uma língua difícil comparada ao japonês ou ao alemão? $O$ padrão de comparação é o inglês. Mesmo aqueles que têm conhecimentos superficiais acerca dessa língua ou aqueles que despenderam anos de esforço para tornarem-se falantes apenas razoáveis de inglês não hesitam em afirmar que o inglês é mais fácil, mais objetivo e mais direto do que o português.

$O$ saber discursivo que produz a imagem da língua portuguesa e da língua inglesa no Brasil apóia-se em concepções aprendidas na escola e concepções que reportam às condições históricas postas pela globalização. $\mathrm{Na}$ relação língua portuguesa e língua inglesa, discursos sobre a dificuldade da primeira e a objetividade da segunda surgem em diferentes formaçòes discursivas.

Os discursos sobre a língua portuguesa, sob a forma de já-ditos no interdiscurso, materializam-se sempre que os sujeitos, em situações determinadas, têm de fazê-la significar. Aparecem no orgulho de ser brasileiro, 
no respeito aquilo que historicamente se construiu no imaginário que sustenta o nacionalismo as tradições e a cultura tanto erudita, quanto popular. Mostramse, por outro lado, apresentando as vantagens da língua inglesa sobre o português, propondo ao imaginário comparaçōes que posicionam a língua portuguesa como difícil, prolixa e pouco prática.

Observamos, assim, que discursos antagônicos mantêm, na ordem simbólica, ideologia semelhante acerca da língua materna, ideologia essa que se alimenta e é alimentada no senso comum (português é muito difícil, não tem lógica, é cheio de regras, etc.) e apoiada oficialmente pelo discurso institucional da língua padrão, patrimônio inatingível. Os que a detêm são estudiosos ou de classe social superior. O que se silencia são os resultados dessa divisão: o privilégio conservado e reproduzido.

O inglês se sustenta em seu prestígio global nào só como promessa de crescimento econômico, mas também dando sustentaçào aos discursos da ciência e da cultura. Essa língua tem uma imagem que a antecede; antes de entrar no discurso, o pré-construído já evoca seu ethos: língua universal, prática, objetiva, necessária.

\section{O papel do professor de língua inglesa}

As condições de produção dos discursos que põem as línguas em relação dizem respeito à ordem mundial: às relações econômicas e aos produtos culturais de comunicação de massa. Os sentidos da relação entram na rede discursiva e se estabelecem enquanto ordem simbólica que Žižec (1996) define como "a forma do pensamento anterior e externa ao pensamento". Os sujeitos nào têm acesso à totalidade da memória (o interdiscurso), eles significam a partir de determinadas posições no interdiscurso, produzem sentidos a partir de determinados traçados da ideologia.

Com base nos pré-construídos que desenham as concepçòes acerca das novas condições de viver no recém chegado milênio o sujeito se identifica como brasileiro e se posiciona, não só em relação à sua cidadania, mas também em relação ao seu lugar no mundo moderno. Em vista disso, o professor de língua inglesa pode partir do senso comum "não sei nem inglês, que dirá português" para ajudar os seus alunos a compreender de forma abrangente sua relação com a sua língua materna e com a língua estrangeira.

Cabe ao professor ajudar o aluno a ler o jogo da linguagem, a vislumbrar que os sentidos podem ser os mesmo (na paráfrase) ou diferentes (na polissemia). O caminho da repetição em que os efeitos de sentido dominam a interpretação, ou o caminho da heterogeneidade pelo qual no percorrer do processo de compreensão das condições que põem em jogo determinados efeitos, as mudanças se façam presentes. 
"NÃO SEI NEM PORTUGUĖS, QUE DIRÁ INGLÊS":

SENTIDOS DE DIZERES RECORRENTES DOS ALUNOS DE LINGUAS

\section{REFERÊNCIAS}

AUTHIER-REVUZ, Jacqueline. Heterogeneidade(s) enunciativa(s). In Cadernos de estudos lingïisticos. Campinas, (p.19) p.25-42, jul./dez, 1990.

. Palavras incertas: as não-coincidências do dizer: Campinas: Editora da

UNICAMP, 1998.

BAGNO, Marcos. Cassandra, Fênix e outros mitos. In FARACO, Carlos Alberto (org.). Estrangeirismos: guerra em torno da lingua. São Paulo: Parábola, 2001.

BAKHTIN, Mikhail. Marxismo e filosofia da linguagem. São Paulo: Hucitec, 1990.

COURTINE, Jean-Jacques. Langages: Analyse du discours politigue (le discours communiste adressé aux chrétiens). n 62 Paris: Larousse, juin 1981.

FARACO, Carlos Alberto (org.). Estrangeirismos: guerra em torno da lingua. São Paulo: Parábola, 2001.

FIORIN, José Luiz. As astúcias da enunciação: as categorias de pessoa, espaço e tempo. São Paulo: Ática, 2001.

HENRY, Paul. A ferramenta imperfeita: lingua, sujeito e discurso. Tradução de Maria Fausta P. Castro, Campinas: Editora da UNICAMP, 1992.

Construções relativas e articulações discursivas. Cadernos de estudos de Lingüistica Aplicada.Campinas, (p.19): Jul/dez, 1990.

INDURSKY, Freda e FERREIRt, Maria Cristina (orgs). Os múltiplos territórios da Análise do discurso. Porto Alegre: SagraLuzzatto, 1999.

ORLANDI. Identidade lingüística e escolar. In: SIGNORINI, Inês (Org).

Lingua(gem) e Identidade: elementos para uma discussão no campo aplicado. Campinas:

Mercado de Letras - Faesp, 2001. Análise do discurso: procedimentos. Campinas: Pontes, 1999.

1996. Interpretação: autoria, leitura e efeitos do trabalho simbólivo. Petrópolis: Vozes,

PÊCHEUX, Michel. O discurso: estrutura ou acontecimento. Campinas: Pontes, 1990a. Semântica e Discurso. Uma critica à afirmação do óbvio. Campinas: Editora da UNICAMP, 1988. 
SCHMITZ, J.R. O projeto de lei 1676/99 na imprensa de São Paulo. In: Estrangeirismos. São Paulo: Parábola, 2001.

ŽIŽEC, Slavoj (org.). Um mapa da ideologia. Rio de Janeiro: Contraponto, 1996. 